\title{
Design of Batch Distillation Columns Using Short-Cut Method at Constant Reflux
}

\author{
Asteria Narvaez-Garcia, ${ }^{1}$ Jose del Carmen Zavala-Loria, ${ }^{2}$ \\ Luis Enrique Vilchis-Bravo, ${ }^{1}$ and Jose Antonio Rocha-Uribe ${ }^{1}$ \\ ${ }^{1}$ Universidad Autonoma de Yucatan, (UADY), Periferico Norte km 33.5, 97203 Merida, YUC, Mexico \\ ${ }^{2}$ Universidad Autonoma del Carmen, (UNACAR), Calle 56 No. 4, Colonia Benito Juarez, 24180 Ciudad del Carmen, CAM, Mexico
}

Correspondence should be addressed to Jose Antonio Rocha-Uribe; antonio.rocha@uady.mx

Received 17 December 2012; Revised 12 March 2013; Accepted 20 March 2013

Academic Editor: M. Angela Meireles

Copyright (c) 2013 Asteria Narvaez-Garcia et al. This is an open access article distributed under the Creative Commons Attribution License, which permits unrestricted use, distribution, and reproduction in any medium, provided the original work is properly cited.

A short-cut method for batch distillation columns working at constant reflux was applied to solve a problem of four components that needed to be separated and purified to a mole fraction of 0.97 or better. Distillation columns with 10, 20, 30, 40, and 50 theoretical stages were used; reflux ratio was varied between 2 and 20. Three quality indexes were used and compared: Luyben's capacity factor, total annual cost, and annual profit. The best combinations of theoretical stages and reflux ratio were obtained for each method. It was found that the best combinations always required reflux ratios close to the minimum. Overall, annual profit was the best quality index, while the best combination was a distillation column with 30 stages, and reflux ratio's of 2.0 for separation of benzene (i), 5.0 for the separation of toluene (ii), and 20 for the separation of ethylbenzene (iii) and purification of o-xylene (iv).

\section{Introduction}

Distillation is the most commonly used separation process in the chemistry and petrochemical industry, mostly employed in continuous processes but also used in discontinuous processes. Batch distillation is widely used for the separation of specialty and fine chemicals and for the recovery of small quantities of solvent during the production of high purity and added value products. Batch processing is the main feature of the pharmaceutical, biochemical, and specialty chemical industries.

One advantage of batch distillation is the possibility to separate a mixture of several components with only one column and, although a batch distillation column uses more energy than a continuous column, many times it is convenient to operate in batch mode. For these reasons the design, analysis, and optimization of batch distillation columns have obtained attention by several researchers.

Figure 1 shows a conventional batch distillation column consisting of a reboiler or pot, a column with plates or packing, a condenser, a reflux tank, accumulative recipients for products (main cuts), and byproducts (off cuts).
In batch distillation columns the feed may be charged into the reboiler at the beginning of the operation and then heat is provided at the reboiler to evaporate part of the liquid to generate a vapor that rises through the column until it reaches the condenser where it is converted to liquid and collected at the reflux tank. From this reflux tank a part is returned to the column as liquid reflux that descends through the column contacting with the vapor counter-currently if the column is full of packing, or contacting the vapor in a crosscurrent pattern if the column contains plates.

Mass transfer occurs when vapor and liquid interact and as a result the light components rise with the vapor and the heavy compounds flow within the liquid. In this way a profile of concentration, temperature, and pressure is drawn throughout the column. At the bottom, pressure and temperature are higher because the heavy compounds have higher boiling points, and because the vapor has a loss of pressure when passing through the packing or plates. The more volatile components concentrate at the top of the column and the less volatile or heavy compounds concentrate at the bottom. These steps at the beginning of the operation are required in order to put the column at total reflux and 


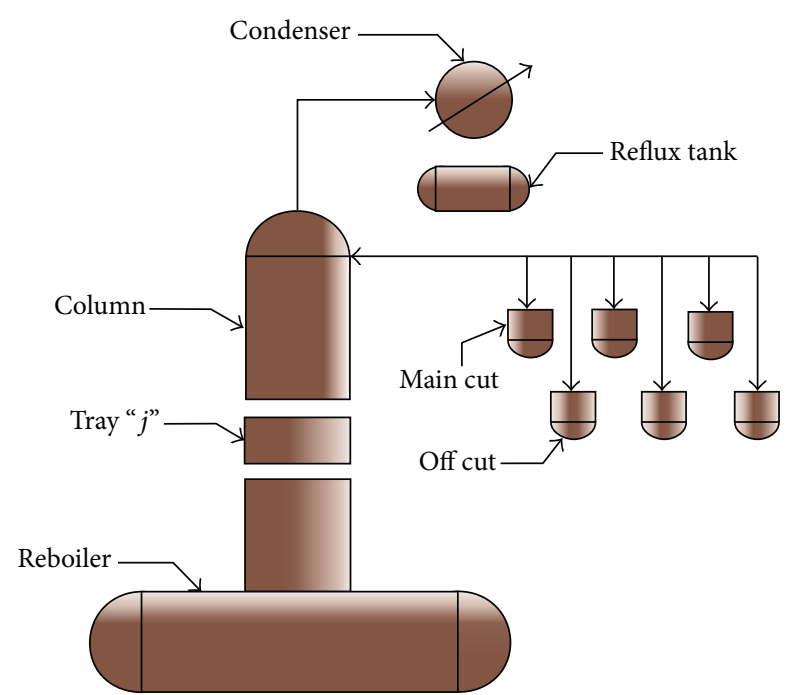

FIGURE 1: Batch distillation column with three receivers for products (main cut) and three receivers for mixtures (off cut).

this operation is used in continuous and batch processes. In normal operation of a batch process, liquid distillate is withdrawn from the reflux tank, taking away the more volatile compounds first and increasing at the same time the concentration of the less volatile or heavy components at the bottom.

The main characteristic of a batch distillation column is that concentrations and temperatures are changing with time at any part of the column.

There are two main operating methods for batch distillation columns: constant reflux (with variable product composition at distillate) and variable reflux (with constant product composition, for one component, at distillated product). Another operating method is the optimal reflux policy, which tries to get an economical combination of the two main operating methods, according to established criteria like: minimum time, maximum product, or maximum profit.

This dynamic process may be modeled by mass and energy balances and coupling them with equilibrium ratios obtained from thermodynamic or experimental vapor-liquid equilibrium data.

The models may vary from McCabe Thiele binary distillation with constant or variable reflux, to short-cut or approximate to rigorous method. Each one has advantages and disadvantages. In this work we use a constant reflux short-cut method to design a batch distillation system (column, condenser, and reboiler) and test three quality indexes: Luyven's capacity factor, total annual cost, and annual profit.

\section{Materials and Methods}

2.1. The Problem. Design (size) a distillation column with condenser and reboiler operating at atmospheric pressure with constant reflux, to separate and purify an equimolar mixture of benzene (i), toluene (ii), ethylbenzene (iii), and oxylene (iv), containing $100 \mathrm{kmol}$ of each, at molar fractions of 0.97 for each component. For vapor liquid equilibrium compare reported data for binary pairs, predicted for multicomponent mixture, versus predicted by Raoult law and ideal gases.

If we receive $400 \mathrm{kmol}$ of the mixture per day, then we would need to size the distillation column filled with sieve trays; we would also need to calculate the area of the condenser and reboiler, as well as the steam and cooling water needed in the condenser. In addition, report Luyben's capacity factor, total annual cost, and annual profit for several alternatives for number of stages, for example, 10, 20, 30, 40 , and 50 theoretical plates, and for several values of reflux ratios.

2.2. Previous Work and Model Description. It was probably Diwekar [1] in her 1988 Ph.D. dissertation who first reported the short-cut method for batch distillation columns, but we think that Diwekar and Madhavan paper [2] is considered the first in a known journal. Their paper described both constant and variable reflux. In 1993, Sundaram and Evans [3] reported their method for simulating batch distillation operation. It only covered constant reflux ratio. Both papers assumed that, at any time, the batch column was identical to the rectifying section of a continuous column and applied the short-cut (FUG) method: Fenske [4], Underwood [5, 6], and Gilliland [7] assuming that the relative volatility of the components remained constant. Both methods began with setting $x_{W_{\mathrm{i}}}=$ $x_{F_{i}}$.

Barolo and Guarice [8] extended their continuous shortcut method to batch distillation columns and used an infinite stage column.

Seader and Henley $[9,10]$ applied Sundaram and Evans [3] method and showed how the FUG equations were used to solve a simulation problem with constant reflux. They presented global (1) and component (i) (2) mass balances:

$$
\begin{gathered}
-\frac{d W}{d t}=D=\frac{V}{R+1}, \\
\frac{d\left(x_{W_{\mathrm{i}}} W\right)}{d t}=x_{D_{\mathrm{i}}} \frac{d W}{d t} .
\end{gathered}
$$

Solving (1) for $W$ (using $k$ for time increment index) and for time (using 0 for initial):

$$
\begin{gathered}
W^{(k+1)}=W^{(k)}-\frac{V}{(R+1)} \Delta t, \\
t=\left(W_{0}-W_{t}\right) \frac{(R+1)}{V} .
\end{gathered}
$$

Solving (2) for $x_{W_{\mathrm{i}}}$ (using $k$ for time increment index) and (i) for any component:

$$
x_{W_{\mathrm{i}}}^{(k+1)}=x_{W_{\mathrm{i}}}^{(k)}+\left(x_{D_{\mathrm{i}}}^{(k)}-x_{W_{\mathrm{i}}}^{(k)}\right)\left[\frac{W^{(k+1)}-W^{(k)}}{W^{(k)}}\right] .
$$

Equations (3) and (5) form the basis of the calculations. Equation (3) gets a new value for total molar mass at the new time at the bottom of the column, and (5) gets the 
concentration of the component (i) at the bottom at the new time.

Luyben [11] did not use the short-cut method but studied and reported simulation results for binary separations covering the following practical aspects of optimal design: number of trays, reflux ratio, tray holdup, and amount of initial charge to the still. For a complete batch cycle he included startup time or equilibration time $\left(t_{E}\right)$, time needed to bring the column to steady state condition on total reflux; overhead product withdrawal or process time $\left(t_{p}\right)$, period during which on-specification distillate product is produced; final bottoms product purification time $\left(t_{F}\right)$, time required to remove enough low boiler from the still pot and column trays so that the bottoms product will be on-specification when the liquid in the column drains down into the still pot. He established that the design objective was to maximize capacity and defined capacity as the amount of total onspecification products produced per unit time (i.e., the sum of distillate and bottoms). He concluded that, as is usually the case in continuous distillation columns, the optimum combination of reflux ratio and number of trays is usually in the direction of several trays and low reflux ratio.

Al-Tuwaim and Luyben [12] used simulation results of a rigorous model for binary and ternary mixtures with the following assumptions: theoretical trays, equimolar overflows, constant relative volatilities, constant tray holdup (1 lbmol), constant reflux drum holdup $(10 \mathrm{lbmol})$, and total slop recycle. Their approach was to find the optimal reflux ratios for columns with various numbers of trays and specify the capacity factor proposed by Luyben [11], which applied for a multicomponent mixture, resulting in the following:

$$
\mathrm{CAP}=\frac{\sum_{j=1}^{N C} P_{j}}{t_{E}+t_{p}+t_{F}+0.5} .
$$

For a given separation we need to specify relative volatility of the system, product purities, energy cost, and material of construction of the column. The authors also used the total annual cost that involves capital cost (column, condenser, and reboiler) and operation cost (steam and cooling water) for a one-year operation period.

In this work, to solve the problem, the strategy was to simulate the operation of a batch distillation column with 10 to 50 theoretical stages and reflux ratios of 2, 5, 10,15 and 20, and rank the runs according with three qualification parameters: Luyben's capacity factor, total annual cost, and annual profit. It was expected that the qualification parameters may point to the most economical combinations of tray and reflux ratio.

From the papers of Diwekar and Madhavan [2] and Sundaram and Evans [3] for constant reflux ratio, we found that both methods were similar and differed only in small details. Seader and Henley $[9,10]$ used the sequence of equations shown in Table 2 that apply FUG method. Gilliland in 1940 [7] presented his results about the relationship between the number of minimum stages and the number of theoretical stages with minimum reflux ratio and operational reflux ratio in graphical form. In 1972, Gilliland's results were correlated by Molokanov et al. [13] and in 1975 by Eduljee [14] with the simpler expression of (g) in Table 2. The book
TABLE 1: Cost of organic compounds (from Turton et al. [18] and Chemical Market Reporter).

\begin{tabular}{lcl}
\hline Chemical & Cost (USD/kg) & $\begin{array}{l}\text { Typical shipping capacity } \\
\text { or basis for price }\end{array}$ \\
\hline Benzene & 0.349 & Barge, Gulf Coast \\
Toluene & 0.322 & Barge, Gulf Coast \\
Ortho-xylene & 0.446 & Railroad tank cars \\
\hline
\end{tabular}

of Mujtaba [15] also covers the short-cut method for batch distillation.

2.3. Equilibrium Ratios and Relative Volatility Used for the Short-Cut Method. For liquid vapor equilibrium we used the binary experimental data reported in Gmehling et al. [16]. We used the reported $y_{1} / x_{1}$ to obtain $K_{1}$ and $\left(1-y_{1}\right) /\left(1-x_{1}\right)$ to obtain $K_{2}$ for each point. From these values we calculated the relative volatility $\gamma=K_{1} / K_{2}$ for each reported point. Higher values of $K_{1}, K_{2}$, and volatilities were obtained at the bottom of the distillation column where the temperature was higher. Table 3 shows the values obtained for the four components in the three separations. It is observed that the most difficult separation was ethylbenzene/o-xylene $(\gamma=1.04)$, while the simpler separation was benzene/toluene $(\gamma=1.34)$.

In order to get relative volatilities for the mixture, we ran simulations of continuous distillation columns using Aspen plus with Peng Robinson and NRTL models that have low deviation ( 0.10 averaged) between experimental and predicted binary data. Table 3 also shows the values predicted by (7) that represents Raoult's Law, at the beginning of the separation at 80 and $110^{\circ} \mathrm{C}$ at the top and bottom of the column, respectively,

$$
K_{j}=\frac{P_{j}^{S}}{P} .
$$

The vapor pressure of each component was predicted by Antoine's equation (8). Constants $a, b, c, d$, and $e$ were taken from Table 23-IV from Yaws [17]

$$
\log P_{j}^{S}=a+\frac{b}{T}+c \log (T)+d T+e T^{2} .
$$

It is observed that all thermodynamic models, such as activity coefficient model (NRTL), equation of state (Peng Robinson), and Raoult Law, predict the same ranking in terms of ease of separation for benzene/toluene and the most difficult for ETB/o-xylene. Also, it is observed that the prediction of ideal gas and ideal liquid behavior predicted by Raoult law is very good, probably because the four components have similar structures as they form part of the aromatic family. From the results of the simulation with Aspen plus we also obtained physical properties at several points of the column.

We decided to take the bottom of the column as the reference for physical properties and for relative volatilities to be used in the short-cut method. When averaged values for relative volatilities were used, the results had the same tendency and the separations improved because $\alpha_{\text {i-ii }}$ increased from 6.33 to 7.16 . 
TABLE 2: Actions and equations used in batch distillation column operating at constant reflux.

\begin{tabular}{|c|c|c|c|}
\hline Step & Action & Sundaram-Evans & Diwekar-Madhavan \\
\hline 0 & Data needed & (a) $N_{c}, \alpha_{i} x_{W, I}, N, R, V, W_{0}$ & \\
\hline $\begin{array}{l}1 \text { (Used to } \\
\text { begin the } \\
\text { cycles) }\end{array}$ & $\begin{array}{l}\text { Using } N \text { as number of } \\
\text { stages, estimate molar } \\
\text { fraction of reference } \\
\text { component at distillate } \\
\left(x_{D, r}\right)\end{array}$ & $\begin{array}{l}\text { (b) } x_{D_{r}}=\frac{x_{W_{r}}}{\sum_{i=1}^{i=C} x_{W_{\mathrm{i}}} \alpha_{i, r}^{N}} \\
r=\text { heaviest component }\end{array}$ & \\
\hline $\begin{array}{l}2 \text { (Used to } \\
\text { begin the } \\
\text { cycles) }\end{array}$ & $\begin{array}{l}\text { Calculate molar fraction of } \\
\text { nonreference component at } \\
\text { distillate }\end{array}$ & (c) Fenske: $x_{D_{\mathrm{i}}}=x_{W_{\mathrm{i}}}\left(\frac{x_{D_{r}}}{x_{W_{r}}}\right) \alpha_{i, r}^{N}$ & $\begin{array}{l}\text { (d) Hengstebek-Geddes: } \\
x_{D}^{\mathrm{i}}=x_{W}^{\mathrm{i}}\left(\frac{\alpha_{i}}{\alpha_{r}}\right)^{C_{1}}\left(\frac{x_{D}^{r}}{x_{W}^{r}}\right)\end{array}$ \\
\hline 3 & $\begin{array}{l}\text { Stepping forward in time } \\
\text { and calculating new molar } \\
\text { mass at bottom and new } \\
\text { molar fraction of all } \\
\text { components }\end{array}$ & $\begin{array}{l}\text { (e) } W^{(k+1)}=W^{(k)}-\left(\frac{V}{1+R}\right) \Delta t \\
\text { (f) } x_{W}^{(k+1)}=x_{W}^{(k)}+\left(x_{D_{\mathrm{i}}}^{(k)}-x_{W_{\mathrm{i}}}^{(k)}\right)\left[\frac{W^{(k+1)}-W^{(k)}}{W^{(k)}}\right]\end{array}$ & \\
\hline 4 & $\begin{array}{l}\text { With Gilliland (Eduljee) } \\
\text { and Underwood, solve } \\
\text { simultaneously for } N_{\min } \\
\text { and } R_{\min }\end{array}$ & $\begin{array}{l}\text { (g) } \frac{N-N_{\min }}{N+1}=0.75\left(1-\left(\frac{R-R_{\min }}{R+1}\right)^{0.5668}\right) \\
\text { (h) } R_{\min }=\frac{\alpha_{1, r}^{N_{\min }}-\alpha_{1, r}}{\left(\alpha_{1, r}-1\right) \sum_{i=1}^{i=r} x_{W_{i}} \alpha_{i, r}^{N_{\min }}}\end{array}$ & \\
\hline 5 & $\begin{array}{l}\text { With the new value of } N_{\min } \text {, } \\
\text { estimate the molar fraction } \\
\text { of the reference component } \\
\text { at distillate }\end{array}$ & (i) $x_{D_{r}}=\frac{x_{W_{r}}}{\sum_{i=1}^{i=C} x_{W_{\mathrm{i}}} \alpha_{i, r}^{N_{\min }}}$ & \\
\hline 6 & $\begin{array}{l}\text { With the new value of } N_{\min } \text {, } \\
\text { calculate molar fraction of } \\
\text { nonreference component at } \\
\text { distillate }\end{array}$ & (j) $x_{D_{\mathrm{i}}}=x_{W_{\mathrm{i}}}\left(\frac{x_{D_{r}}}{x_{W_{r}}}\right) \alpha_{i, r}^{N_{\min }}$ & \\
\hline 7 & $\begin{array}{l}\text { Repeat steps } 3 \text { to } 6 \text { for } \\
\text { several cycles. }\end{array}$ & & \\
\hline 8 & Stop & & \\
\hline
\end{tabular}

Computer programs in Excel, Mathcad, and Visual Basic were created with the equations of Table 2 and were applied to simulate the batch columns that fixed the value of the boilup vapor at $100 \mathrm{kmol} / \mathrm{hr}$ and varied the number of theoretical plates $(10,20,30,40,50)$ and external reflux ratio $(L / D=2$, $5,10,15,20)$. They were initially applied for the separation of component (i) (benzene), the lightest component with a purity of 0.97 in mass fraction.

\subsection{Quality Indexes for Batch Distillation Column Operation}

2.4.1. Luyben Capacity Factor for Comparison. Application of (6), neglecting equilibrium time (time needed to bring the column to steady state conditions on total reflux), and assigning 1 hour for feed and cleaning result in the following:

$$
\mathrm{CAP}=\frac{P_{\mathrm{i}}+P_{\mathrm{ii}}+P_{\mathrm{iii}}+P_{\mathrm{iv}}}{t_{\mathrm{i}}+t_{\mathrm{i}-\mathrm{ii}}+t_{\mathrm{ii}}+t_{\mathrm{ii}-\mathrm{iii}}+t_{\mathrm{iii}}+t_{\mathrm{iii}-\mathrm{iv}}+t_{f-\mathrm{c}}} .
$$

The numerator shows the molar or mass amounts of products that satisfy the desired concentration, while the denominator is made up of three different parameters: the harvest time for each product $\left(t_{\mathrm{i}}, t_{\mathrm{ii}}, t_{\mathrm{iii}}\right.$, and $\left.t_{\mathrm{iv}}\right)$ that are collected on the main cut receivers, the time required to eliminate a volatile component $\left(t_{\mathrm{i}-\mathrm{ii}}, t_{\mathrm{ii} \text {-iii }}\right.$, and $\left.t_{\mathrm{iii} \text {-iv }}\right)$ whose mixtures are discharged on the off cut tanks, and the time needed for feeding and discharging the batch distillation column $\left(t_{f \cdot c}\right.$, which equals 1 hour). It should be noted that $t_{\text {iii-iv }}$ is the time elapsed after the concentration of ethylbenzene drops below 0.97 and the time the concentration of xylene at bottom reaches 0.97 .

2.4.2. Total Annual Cost for Comparison. Total annual cost given by

$$
\begin{aligned}
\text { TAC }=\text { Annual cost of equipment } \\
\\
+ \text { Annual cost of utilities }
\end{aligned}
$$

is an index used for comparison of alternatives. It takes into account the annual capital cost of equipment: distillation column (plates and shell), reboiler, and condenser, and also 
TABLE 3: Equilibrium constant and relative volatilities for the mixture: benzene, toluene, ethylbenzene, and o-xylene at atmospheric pressure.

\begin{tabular}{|c|c|c|c|c|c|c|c|c|c|c|c|c|c|c|}
\hline & \multicolumn{2}{|c|}{ Binary data } & \multicolumn{3}{|c|}{ Peng R. $83-125^{\circ} \mathrm{C}$} & \multicolumn{3}{|c|}{ NRTL $83-125^{\circ} \mathrm{C}$} & \multicolumn{3}{|c|}{$\begin{array}{c}\text { Raoult } \\
\text { Top } 80^{\circ} \mathrm{C}\end{array}$} & \multicolumn{3}{|c|}{$\begin{array}{c}\text { Raoult } \\
\text { Bottom } 110^{\circ} \mathrm{C}\end{array}$} \\
\hline & $\mathrm{Ki}$ & $\alpha \mathrm{i}$ & $\mathrm{Ki}$ & $\alpha \mathrm{i}$ & $\alpha \mathbf{i j}$ & $\mathrm{Ki}$ & $\alpha \mathrm{i}$ & $\alpha \mathbf{i j}$ & $\mathrm{Ki}$ & $\alpha \mathrm{i}$ & $\alpha \mathbf{i j}$ & $\mathrm{Ki}$ & $\alpha \mathrm{i}$ & $\alpha \mathbf{i j}$ \\
\hline \multirow[t]{2}{*}{ Benzene } & 1.51 & & 2.07 & & 5.91 & 2.08 & & 6.30 & 1.00 & & 8.00 & 2.28 & & 6.33 \\
\hline & & 1.34 & & 2.35 & & & 2.19 & & & 2.63 & & & 2.38 & \\
\hline \multirow[t]{2}{*}{ Toluene } & 1.13 & & 0.88 & & 2.51 & 0.90 & & 2.73 & 0.38 & & 3.04 & 0.96 & & 2.66 \\
\hline & & 1.19 & & 1.95 & & & 1.99 & & & 2.30 & & & 2.09 & \\
\hline \multirow[t]{2}{*}{ ETB } & 0.95 & & 0.45 & & 1.29 & 0.41 & & 1.24 & 0.17 & & 1.32 & 0.46 & & 1.28 \\
\hline & & 1.04 & & 1.29 & & & 1.26 & & & 1.32 & & & 1.28 & \\
\hline O-Xileno & 0.91 & & 0.35 & & 1.00 & 0.33 & & 1.00 & 0.13 & & 1.00 & 0.36 & & 1.00 \\
\hline
\end{tabular}

annual operating cost (steam for reboiler and cooling water for condenser). With the boilup fixed at $V=100 \mathrm{kmol} / \mathrm{h}$ and external reflux ratio $R=L / D$ specified, liquid flow rate $(L=R * D)$ and internal ratio $\mathrm{L} / \mathrm{V}$ may be calculated as

$$
\frac{L}{V}=\frac{R \cdot D}{R \cdot D+D}=\frac{R}{R+1}
$$

With the molar flow rates of liquid and vapor, the diameter of the column may be calculated using physical properties $(\rho$, $\mu, \sigma)$ and geometric parameters to predict flooding velocity $\left(U_{f}\right)$ and fixing operational vapor velocity as a fraction $(f)$ of it, the column diameter is

$$
D_{\mathrm{col}}=\sqrt{\frac{4 \cdot V \cdot M_{v}}{f \cdot U_{f} \cdot \pi \cdot\left(1-A_{d} / A_{\mathrm{col}}\right) \cdot \rho_{V}}} .
$$

With the molar flow of the vapor $V$ that needed to be condensed and the heat of condensation of distillate vapor, $Q_{C}$ was calculated, and from it $A_{C}$ was determined with the heat transfer equation. Additionally, the flow rate of cooling water was obtained

$$
Q_{C}=V \cdot \Delta H_{\text {cond }}=U_{C} \cdot A_{C} \cdot \Delta T_{C}=m_{C W} \cdot C_{P_{\mathrm{CW}}} \cdot \Delta T_{C W} \cdot
$$

At the bottom of the column heat was needed to vaporize $V \mathrm{kmol} / \mathrm{h}$ of the liquid and with the heat of vaporization of the liquid at the bottom we obtained $A_{R}$, as well as the flow rate of the steam needed as main utility as follows:

$$
\begin{aligned}
Q_{R} & =V \cdot \Delta H_{\text {vap-bottom mixture }} \\
& =U_{R} \cdot A_{R} \cdot \Delta T_{R}=m_{\text {steam }} \cdot \Delta H_{\text {vap-steam }} .
\end{aligned}
$$

In order to identify the runs, the following nomenclature was used:

N IJK, where:

$$
N=\text { Number of theoretical stages, }
$$

$I=$ Reflux ratio used in the first separation: distillation of benzene (i) from (ii), (iii), and (iv) (4 components). For this separation we used $R=2 \rightarrow A, R=5 \rightarrow B$, $R=10 \rightarrow C, R=15 \rightarrow D, R=20 \rightarrow E$,
$J=$ Reflux ratio used in the second separation: distillation of (ii) from (iii) and (iv) (3 components),

$K=$ Reflux ratio used in the third and last separation of (iii) from (iv) (2 components). For this separation the reflux ratios 2.0 and 5.0 are smaller than the minimum reflux and the distillation column cannot operate, then we used $R=10 \rightarrow C, R=15 \rightarrow D$, $R=20 \rightarrow E$.

As an example, $20 \mathrm{ABC}$ means a distillation column with 20 theoretical stages, $R=2$ (A) for the first separation (four components), $R=5$ (B) for the second separation (three components), and $R=10$ (C) for the third separation (two components).

2.4.3. Annual Profit for Comparison. A complete economical analysis would require the calculation of annual gain or profit:

Annual profit $=$ total annual income - total annual cost.

Annual income is the amount of money collected when the four harvested products are sold. Table 6.4 of Turton et al. [18] provides averaged values from the Chemical Market Reporter for January-April, 2001 see Table 1.

The selling price for ethylbenzene was assumed to be equal to that of ortho-xylene.

\section{Results and Discussion}

3.1. Four Components Separation. Figures 2(a) and 2(b) show the results for a batch distillation column operating at constant reflux ratio of 2.0 with ten theoretical stages. In Figure 2(a) it is observed that at the bottom of the column, the composition of benzene decreased with time while the composition of the heavy components increased. In Figure 2(b) it is observed that the instant distillate composition of benzene was 1.0 at the beginning and then decreased to 0.86 at 2.2 hours, which was the last time reported, but the averaged composition of benzene remained above 0.97 all this time. We call this harvest time. It is observed that the larger changes in distillate composition occurred close to the final time. 


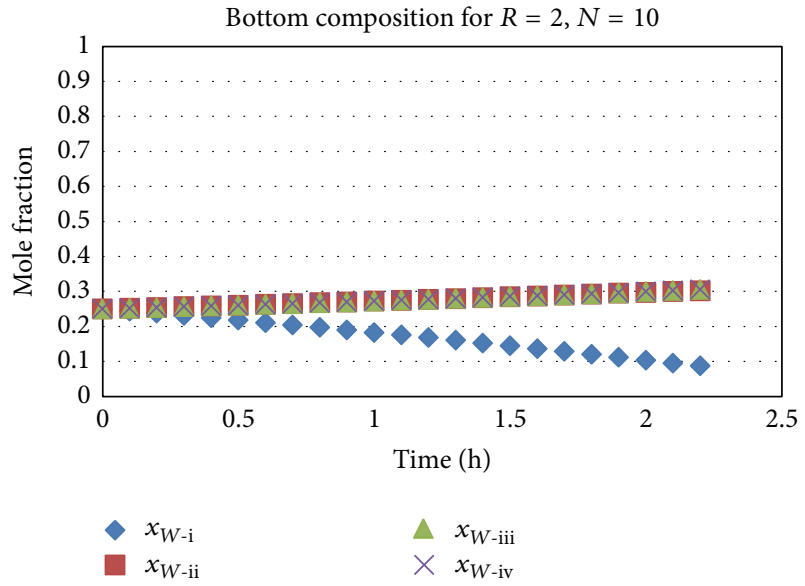

(a)

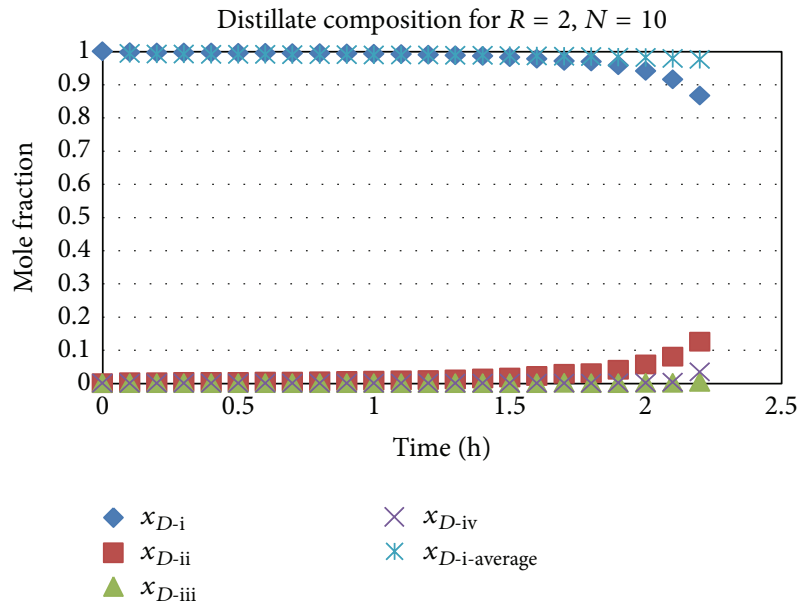

(b)

FIGURE 2: Results for four components batch distillation with short-cut method at constant reflux of 2.0; (a) bottom composition, (b) distillate composition.

As observed in step four of Table 2, the computer program was needed to solve ( $\mathrm{g}$ ) in Table 2 for minimum reflux ratio with the Gilliland Eduljee correlation $R_{\min -G}$ and compare it with the result of $(\mathrm{h})$ in Table 2 for minimum reflux ratio with the Underwood correlation $R_{\min -U}$. Once $(\mathrm{g})$ and $(\mathrm{h})$ in Table 2 were solved, the results were used to find the number of minimum stages $\left(N_{\min }\right)$ that should be applied in other steps of the method.

In the first iterations we began with $N_{\text {min }}=N / 2=$ 5 , minimum reflux from Gilliland-Eduljee provided a value of $R_{\min -G}=1.42$ and $R_{\min -U}=0.74$. Using successive substitution we calculated the new values $N_{\min }=6.7956$ and for this value we obtained $R_{\min -G}=0.7400$ and $R_{\min -U}=$ 0.7484 and a new value for $N_{\min }=6.7766$. The last values for the first iteration were $N_{\min }=6.7766, R_{\min -G}=0.7483$, and $R_{\min -U}=0.7483$.

In the process, time was increasing and $N_{\text {min }}$ decreased from 6.77 to 2.25 at the last time reported ( 2.2 hours), but minimum reflux $\left(R_{\min }\right)$ of Gilliland and Underwood was gradually increasing starting from about 0.75 . Once the value of the Underwood minimum reflux or Guilliland-Eduljee equals or surpasses the value of the fixed operational reflux (2.0 in this case), the term $\left(R-R_{\min }\right)$ in Gilliland correlation turns negative and hence the program cannot continue with the calculations. Fortunately, the calculations performed before this point provided all the useful information we needed.

Figures 3 and 4 help us compare the use of different reflux ratios. Figures $3(\mathrm{a})$ and $3(\mathrm{~b})$ show the results for a column with $N=10$ and $R=2,5,10$ while Figures $4(\mathrm{a})$ and 4(b) show the same results but using $N=40$.

Figures 3(a) and 4(a) are very similar. They show that for a constant reflux of 2.0 the original bottom is depleted from $400 \mathrm{kmol}$ to 327 and $330 \mathrm{kmol}$ for $N=10$ and $N=$ 40 , respectively. The difference between the original $W_{o}=$ $400 \mathrm{kmol}$ and amount remaining at the bottom appears as distillate harvested $=73$ and $70 \mathrm{kmol}$ of a mixture of benzene with a little of toluene for $N=10$ and $N=40$.

For reflux ratios of 5 and 10 and the same number of theoretical stages, more distillate product with $x_{D_{i}} \geq 0.97$ was obtained, but also more time was needed. Since the beginning of this first distillation the harvested benzene product goes to main cut 1 tank of Figure 1 and at harvest time the distillate is deviated to the off cut 1 tank where a mixture of benzene, toluene and a little of ethylbenzene was kept.

In order to know the time needed for all the benzene to disappear in the bottom of the column with $R=2.0$, we extrapolated the data of $x_{W \text {-i }}$ versus time in Figure 2(a) obtaining first equation:

$$
x_{W-\mathrm{i}}=0.2498-0.0605 \cdot t-0.0068 \cdot t^{2} .
$$

And then solving for $x_{W-\mathrm{i}}=0.0$, we find that about 3.0 hours are needed to eliminate all the benzene from the bottom. Nonetheless, it is likely that some benzene will be at the plates of packing of the column. Assuming that we were able to separate in the first distillation the $100 \mathrm{kmol}$ of benzene, solving (4) for $W_{t}=300$, we get $t=3.0$ hours.

The time needed for the elimination of benzene from the four-component original mixture is a rough approximation. When comparing a rigorous method versus a short-cut method, usually the first uses more time than the second. Also, when benzene is being depleting from the reboiler the other light components, such as toluene and ethylbenzene are being separated in the later stages of the distillation column.

Also in the approximation taken, we found that the composition of the three compounds that remained at the bottom (toluene, ethylbenzene, and o-xylene) had the same composition: $x_{W-\mathrm{i}} \approx 0.333$.

Applying the same procedure for $R=5$ and $R=10$ provided $t=6$ and 11 hours, respectively to eliminate the benzene from the bottom of the column $\left(x_{W-i}=0\right)$. Also 


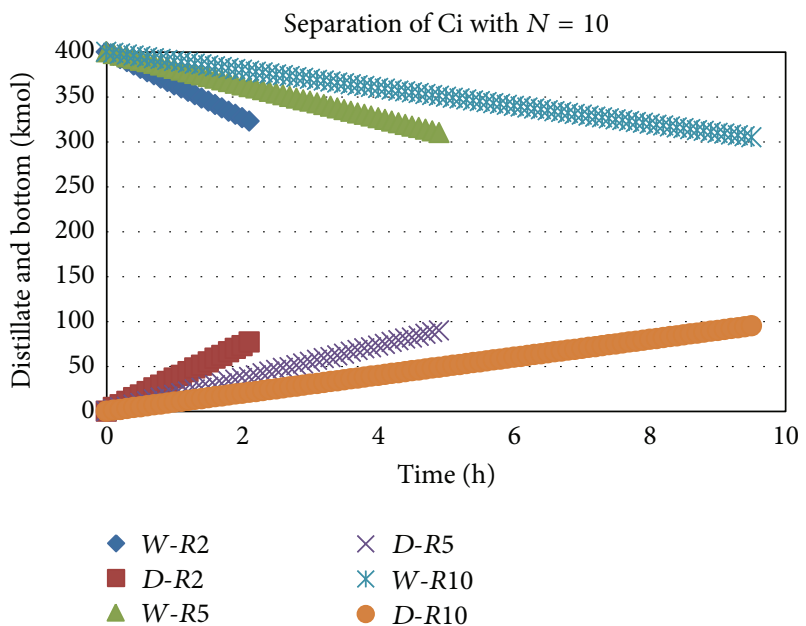

(a)

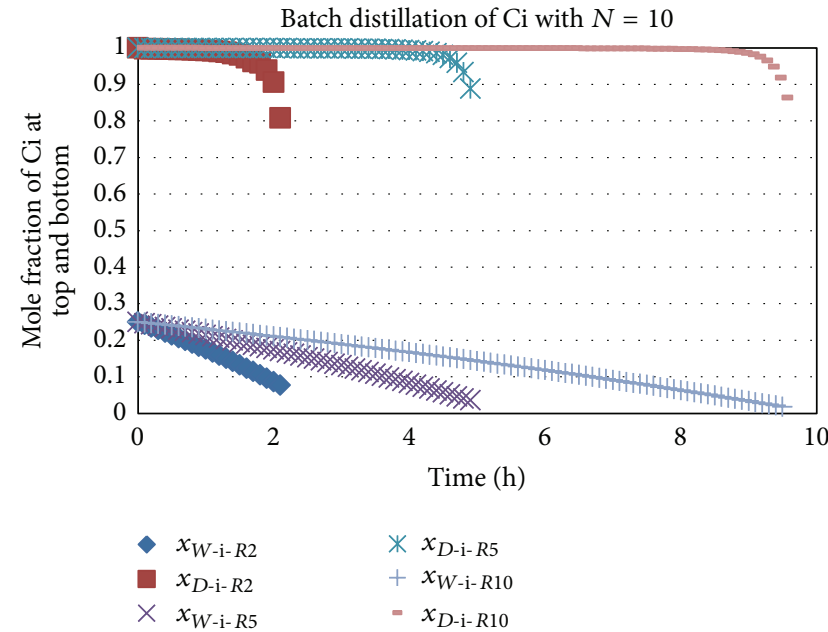

(b)

FIGURE 3: Results for four components batch distillation at reflux ratios of 2, 5, and 10 for a column with 10 theoretical stages.

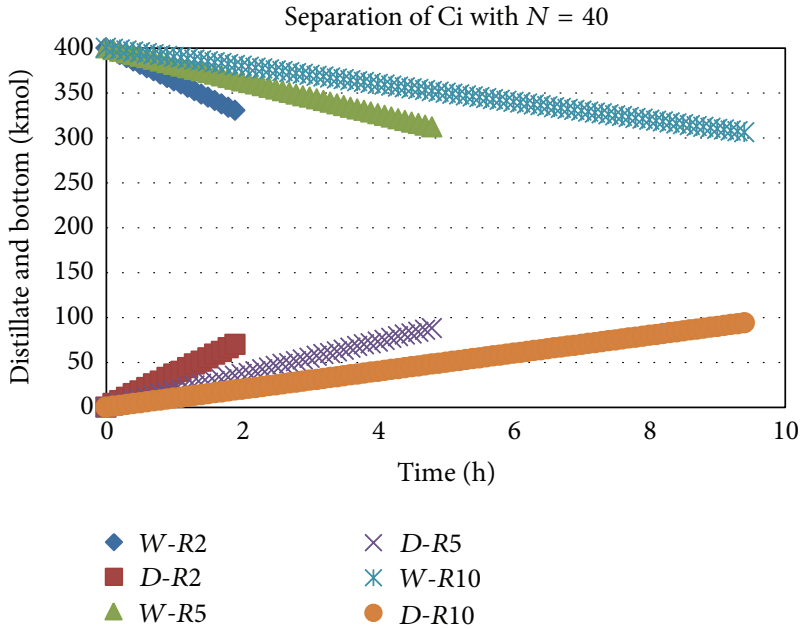

(a)

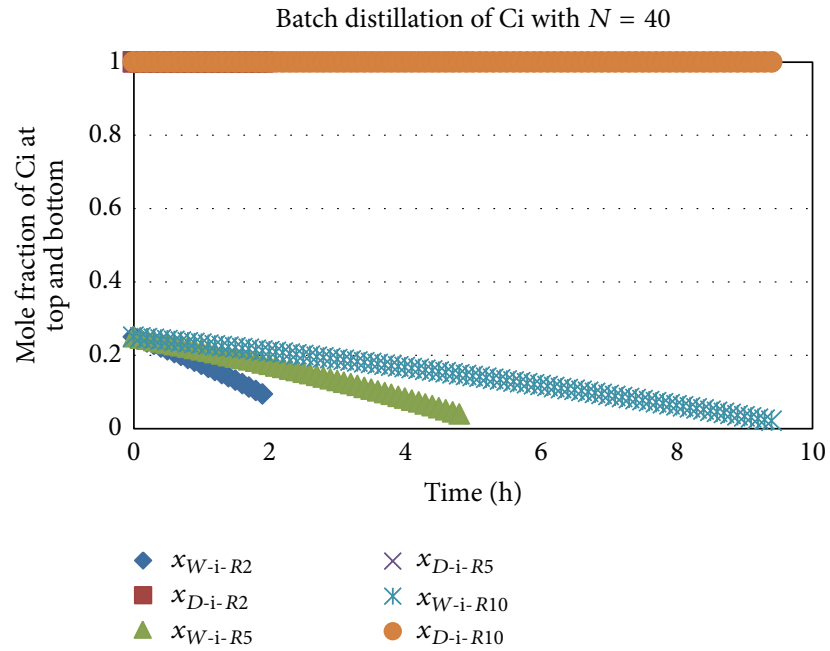

(b)

FIGURE 4: Results for four components batch distillation at reflux ratios of 2, 5, and 10 for a column with 40 theoretical stages.

the molar fraction of the other components tended to be equimolar at 0.333 .

Figures 3(b) and 4(b) show that with the combination of low reflux $R=2$ and low number of theoretical stages $N=10$ distillate composition drops below 0.90 , but for the combination of $N=40$ and $R=2$ the punctual composition for benzene in distillate is always close to unity for the three values of reflux ratio. Similar results were performed for $N=$ 30 and 50 .

Table 4 show harvest time and collected products for the different alternatives in this four-components separation. It is observed that with more reflux, better product (with $x_{W \text {-i }} \geq$ 0.97 ) is collected but harvested and total time increase with respect to the lowest reflux of 2.0. It is possible to calculate a partial Luyben index $\left(\mathrm{P}_{4}\right.$-CAP) for the four components separation by dividing the collected benzene product by the total time for the run.

3.2. Three Components Separation. Beginning with $W_{0}=$ $300 \mathrm{kmol}$ we run the program first for $N=10$ and $R=2$ and observe that the first molar fraction of component ii (toluene) is 0.9995 , the second molar fraction drops to 0.9538 , and then the average composition is lower than the required 0.97 . We see that this combination of stages and reflux is not enough to get the desired molar fraction of toluene distillate. This happens because the relative volatility for three components is lower (2.09) than the one for four components (2.38), and we may anticipate also difficulties for the two component separation with relative volatility of only 1.28. 
TABLE 4: Four-component separation: benzene (i), toluene (ii), ethylbenzene (iii), and o-xylene (iv) at constant reflux.

\begin{tabular}{|c|c|c|c|c|c|c|c|c|}
\hline Case & $R=L / D$ & Feed $=W_{0}(\mathrm{kmol})$ & $t$ harvest (h) & $t$ total $(\mathrm{h})$ & $W_{t}(\mathrm{kmol})$ & $P_{\mathrm{i}}(\mathrm{kmol})$ & $\begin{array}{c}\mathrm{P}_{4}-\mathrm{CAP} \\
\mathrm{kg} / \mathrm{h}\end{array}$ & $\begin{array}{l}\text { CTA } \\
\text { USD } \\
\end{array}$ \\
\hline \multicolumn{9}{|c|}{$N=20$} \\
\hline A & 2 & 400 & 2.1 & 3 & 300 & 70.00 & 1883 & 493,757 \\
\hline B & 5 & 400 & 5.3 & 6 & 300 & 88.33 & 1148 & 874,550 \\
\hline $\mathrm{C}$ & 10 & 400 & 10.3 & 11 & 300 & 93.63 & 677 & $1,508,046$ \\
\hline \multicolumn{9}{|c|}{$N=30$} \\
\hline A & 2 & 400 & 2.1 & 3 & 300 & 70.00 & 1883 & 503,206 \\
\hline $\mathrm{B}$ & 5 & 400 & 5.3 & 6 & 300 & 88.33 & 1148 & 884,009 \\
\hline $\mathrm{C}$ & 10 & 400 & 10.3 & 11 & 300 & 94.54 & 677 & $1,517,531$ \\
\hline \multicolumn{9}{|c|}{$N=40$} \\
\hline $\mathrm{A}$ & 2 & 400 & 2.1 & 3 & 300 & 70.00 & 1883 & 512,486 \\
\hline B & 5 & 400 & 5.3 & 6 & 300 & 88.33 & 1148 & 893,299 \\
\hline $\mathrm{C}$ & 10 & 400 & 10.3 & 11 & 300 & 94.54 & 677 & $1,508,046$ \\
\hline \multicolumn{9}{|c|}{$N=50$} \\
\hline $\mathrm{A}$ & 2 & 400 & 2.1 & 3 & 300 & 70.00 & 1883 & 521,676 \\
\hline B & 5 & 400 & 5.3 & 6 & 300 & 88.33 & 1148 & 902,498 \\
\hline $\mathrm{C}$ & 10 & 400 & 10.4 & 11 & 300 & 94.54 & 677 & $1,536,028$ \\
\hline
\end{tabular}

We are going to see, when we run the separation for the binary mixture of ethylbenzene o-xylene, that the reflux ratios of 2.0 and 5.0 will not be enough to get good product $\left(x_{W \text {-ii }} \geq 0.97\right)$ and only with the reflux ratio of 10.0 we get the desired molar fraction above 0.97 . In order to get more points to analyze we add reflux ratios of 15 and 20 and use the columns with $N=20,30,40$, and 50 .

Using a distillation column with 20 stages with reflux ratio of 2.0 we get good compositions (above 0.97 ) and we got a harvest time of 0.6 hours and collected $20 \mathrm{kmol}$ of toluene. Extrapolating the composition of toluene at bottom we need 3.3 hours, and using (4) we need 3.0 hours to distillate other $100 \mathrm{kmol}$ that represents all the toluene feed.

In order to simplify the comparison between all runs we are going to assume that (4) predicts well the total time to distillate a product and that the components will remain in equimolar proportion.

All combinations with 20,30, 40, and 50 stages and reflux ratios of $2,5,10,15$, and $20(\mathrm{~A}, \mathrm{~B}, \mathrm{C}, \mathrm{D}$, and $\mathrm{E})$ work fine and the results are shown in Table 5.

Again, for a batch distillation at constant reflux with a fixed number of theoretical stages, when the reflux ratio increases the harvested product increases, but also the harvested and total time increase. The results on harvested product, harvest time, and total time are very similar for all the cases with $N=20,30,40$, and 50 and then the partial Luyben factor $\mathrm{P}_{3}$-CAP for the three component separation is also very close for the same reflux ratio.

3.3. Two-Component Separation. Now only ethylbenzene and o-xylene remain and we are going to assume that we have 200 $\mathrm{kmol}$ of an equimolar mixture.
Figure 5 shows the results for the simulation with $N=$ 20 and $R=10$. It is observed that molar fraction of ethylbenzene at the distillate remains above 0.97 only 0.5 hours. We only collect $4.55 \mathrm{kmol}$ of ethylbenzene. We need to turn the following distillate to off cut 3 that will contain ethylbenzene and o-xylene. We need to do this until we get o-xylene with molar fraction above 0.97 in the bottom of distillation column. We may extrapolate $x_{W \text {-iii }}$ versus time, until it is zero, or we may extrapolate $x_{D \text {-iii }}$ versus time until it is zero. The first one will assure that there are no ethylbenzene at the bottom and gives $t=13.69$ hours. The other means that there is no ethylbenzene at the bottom and at the plates or packing of the column and will be $t=13.87$ hours; we get $73 \mathrm{kmol}$ of o-xylene with $x_{W \text {-iv }} \geq 0.97$.

Table 6 shows the results for this binary separation of ethylbenzene and xylene including the two harvested products (iii) and (iv), the time for harvest component (iii) at distillate and the time to harvest (iv) at bottom.

3.4. Luyben Capacity Factor, (CAP). With the information on Tables 4-6 the Luyben Capacity factor may be calculated for any combination. By example $20 \mathrm{ABC}$ is the batch distillation column with 20 theoretical stages, $R=2$ for the first separation, $R=5$ for the second separation, and $R=10$ for the third separation. Application of (10) gives the capacity factor en $\mathrm{kmol} / \mathrm{h}$ as follows:

$$
\mathrm{CAP}_{20 \mathrm{ABC}}=\frac{70+73.33+4.54+72}{3+6+14}=9.56
$$

Table 7 provides Luyben capacity factor (CAP) for most of the combination studied and Figure 6 shows best and worst cases. Best Luyben capacity factor uses low reflux ratio and high number of theoretical stages. 
TABLE 5: Three components separation: toluene (ii), ethylbenzene (iii), and xylene (iv) at constant reflux.

\begin{tabular}{|c|c|c|c|c|c|c|c|c|}
\hline Case & $R=L / D$ & Feed $=W_{0}(\mathrm{kmol})$ & $t$ harvest (h) & $t$ total $(\mathrm{h})$ & $W_{t}(\mathrm{kmol})$ & $P_{\mathrm{ii}}(\mathrm{kmol})$ & $\begin{array}{c}\mathrm{P}_{3}-\mathrm{CAP} \\
\mathrm{kg} / \mathrm{h}\end{array}$ & $\begin{array}{l}\text { CTA } \\
\text { USD }\end{array}$ \\
\hline \multicolumn{9}{|c|}{$N=20$} \\
\hline A & 2 & 300 & .6 & 3 & 200 & 20.00 & 614 & 496,841 \\
\hline B & 5 & 300 & 4.4 & 6 & 200 & 73.33 & 1126 & 888,801 \\
\hline $\mathrm{C}$ & 10 & 300 & 9.6 & 11 & 200 & 87.27 & 730 & $1,539,172$ \\
\hline $\mathrm{D}$ & 15 & 300 & 14.5 & 15.9 & 200 & 90.62 & 525 & $1,366,393$ \\
\hline $\mathrm{E}$ & 20 & 300 & 19.4 & 21 & 200 & 92.38 & 405 & $1,439,891$ \\
\hline \multicolumn{9}{|c|}{$N=30$} \\
\hline A & 2 & 300 & .6 & 3 & 200 & 20.00 & 614 & 504,500 \\
\hline B & 5 & 300 & 4.4 & 6 & 200 & 73.33 & 1126 & 896,700 \\
\hline $\mathrm{C}$ & 10 & 300 & 9.6 & 11 & 200 & 87.27 & 730 & $1,539,000$ \\
\hline $\mathrm{D}$ & 15 & 300 & 14.6 & 15.9 & 200 & 91.25 & 528 & $2,273,369$ \\
\hline $\mathrm{E}$ & 20 & 300 & 19.55 & 20.5 & 200 & 93.09 & 418 & $2,658,262$ \\
\hline \multicolumn{9}{|c|}{$N=40$} \\
\hline A & 2 & 300 & .6 & 3 & 200 & 20.00 & 614 & 512,486 \\
\hline B & 5 & 300 & 4.4 & 6 & 200 & 73.33 & 1126 & 906,834 \\
\hline $\mathrm{C}$ & 10 & 300 & 9.6 & 11 & 200 & 87.27 & 730 & $1,556,655$ \\
\hline $\mathrm{D}$ & 15 & 300 & 14.6 & 16 & 200 & 93.09 & 535 & $2,183,616$ \\
\hline $\mathrm{E}$ & 20 & 300 & 19.55 & 20 & 200 & 93.05 & 428 & $2,720,369$ \\
\hline \multicolumn{9}{|c|}{$N=50$} \\
\hline A & 2 & 300 & .6 & 3 & 200 & 20.00 & 614 & 523,077 \\
\hline B & 5 & 300 & 4.4 & 6 & 200 & 73.33 & 1126 & 915,390 \\
\hline $\mathrm{C}$ & 10 & 300 & 9.6 & 11 & 200 & 87.27 & 730 & $1,565,265$ \\
\hline $\mathrm{D}$ & 15 & 300 & 14.6 & 16 & 200 & 91.25 & 525 & $2,192,452$ \\
\hline E & 20 & 300 & 19.5 & 20 & 200 & 93.05 & 428 & $2,775,651$ \\
\hline
\end{tabular}

3.5. Total Annual Cost, (TAC). The CAPCOST computer program from Turton et al. book [18] was used to estimate the cost of distillation column with sieve trays, condenser, and reboiler. It was assumed that the equipment will last for 10 years and then the contribution for one year was calculated by dividing the cost between the depreciation period. From Table 6.3 the cost for low pressure steam at 5 bars and $160^{\circ} \mathrm{C}$ was fixed at $16.22 \mathrm{USD} / 1000 \mathrm{~kg}$, and the cost for cooling water was $14.8 \mathrm{USD} / 1000 \mathrm{~m}^{3}$.

Table 7 shows calculated values for TAC for all the runs and Figure 6 presents best and worst cases.

It is observed that best total annual cost uses low reflux ratio (20AAD, 30AAE) and low number of theoretical stages, although some good combinations use 40 and 50 theoretical stages (40AAE and 50AAC). These alternatives require low energy at the reboiler and offer low TACs.

Luyben capacity factor only takes into account harvest product and processing time. It does not consider cost of the column, reboiler, and condenser, or cost of steam and cooling water. Meanwhile total annual cost it has into account cost of equipment and operational cost of utilities, but ignore harvested product.

This finding of best cases for TAC and Luyben CAP using low reflux ratio and a given number of theoretical stages is analogous to continuous distillation columns that locate the optimum operational reflux ratio at values given by (18), Peters and Timmerhaus [19].

$$
R_{\text {optimum }}=(1.1 \text { to } 1.3) R_{\min } \text {. }
$$

As the reflux ratio is increased from the minimum value, the number of plates decreased, the column diameter increases, and the reboiler steam and condenser cooling-water requirements increase. Although the numerical value for reboiler and condenser duty is similar, the annual cost of steam is close to ten times the cost of cooling water. Then, the total annual cost is dominated by the cost of steam.

3.6. Annual Profit, (AP). With harvested data in kmol for each compound, converted to $\mathrm{kg}$ and to money with the selling price, then with the total amount of time needed for one run and assuming that in one year the plant will operate 7872 hours (about $90 \%$ of the time) the total annual income is calculated. The total annual cost is subtracted to this number and we get the annual profit.

Table 7 resumes annual profit for all the runs and Figure 6 shows best and worst cases for the three qualifying parameters. 
TABLE 6: Two components separation: ethyl benzene (iii) and xylene (iv) at constant reflux.

\begin{tabular}{|c|c|c|c|c|c|c|c|c|c|c|}
\hline Case & $R=L / D$ & $\begin{array}{l}\text { Feed }=W_{0} \\
\quad(\mathrm{kmol})\end{array}$ & $\begin{array}{l}t \text { harvest } \\
\text { (h) }\end{array}$ & $\begin{array}{l}t \text { total } \\
(\mathrm{h})\end{array}$ & $W_{t}(\mathrm{kmol})$ & $\begin{array}{c}P_{\mathrm{iii}} \text { Harvested } \\
\text { ethyl benzene } \\
(\mathrm{kmol})\end{array}$ & $\begin{array}{c}\mathrm{P}_{2} \text {-CAP } \\
\mathrm{kg} / \mathrm{h}\end{array}$ & $\begin{array}{l}\text { CTA } \\
\text { USD }\end{array}$ & $\begin{array}{l}t \text { final } \\
\text { Xylene } \\
\text { (h) }\end{array}$ & $\begin{array}{c}P_{\text {iv }} \text { Harvested } \\
\text { Xylene } \\
(\mathrm{kmol})\end{array}$ \\
\hline \multicolumn{11}{|c|}{$N=20$} \\
\hline A & 2 & $\mathrm{X}$ & $\mathrm{X}$ & $\mathrm{X}$ & $\mathrm{X}$ & $\mathrm{X}$ & $\mathrm{X}$ & $\mathrm{X}$ & $\mathrm{X}$ & $\mathrm{X}$ \\
\hline B & 5 & $\mathrm{X}$ & $\mathrm{X}$ & $\mathrm{X}$ & $\mathrm{X}$ & $\mathrm{X}$ & $\mathrm{X}$ & $\mathrm{X}$ & $\mathrm{X}$ & $\mathrm{X}$ \\
\hline $\mathrm{C}$ & 10 & 200 & .5 & 11 & 100 & 4.54 & 38 & $1,947,574$ & 14 & 72 \\
\hline $\mathrm{D}$ & 15 & 200 & 7.5 & 10 & 100 & 46.87 & 389 & $1,427,695$ & 16.4 & 80.3 \\
\hline $\mathrm{E}$ & 20 & 200 & 14.2 & 15.5 & 100 & 67.61 & 401 & $2,274,166$ & 20.1 & 88 \\
\hline \multicolumn{11}{|c|}{$N=30$} \\
\hline A & 2 & $\mathrm{X}$ & $\mathrm{X}$ & $\mathrm{X}$ & $\mathrm{X}$ & $\mathrm{X}$ & $\mathrm{X}$ & $\mathrm{X}$ & $\mathrm{X}$ & $\mathrm{X}$ \\
\hline B & 5 & $\mathrm{X}$ & $\mathrm{X}$ & $\mathrm{X}$ & $\mathrm{X}$ & $\mathrm{X}$ & $\mathrm{X}$ & $\mathrm{X}$ & $\mathrm{X}$ & $\mathrm{X}$ \\
\hline $\mathrm{C}$ & 10 & 200 & 6.4 & 11 & 100 & 58 & 485 & $1,824,041$ & 13 & 81 \\
\hline $\mathrm{D}$ & 15 & 200 & 10.4 & 13.5 & 100 & 65 & 443 & $2,175,215$ & 14 & 84 \\
\hline $\mathrm{E}$ & 20 & 200 & 15.8 & 15.6 & 100 & 75.23 & 444 & $1,500,652$ & 20.7 & 91 \\
\hline \multicolumn{11}{|c|}{$N=40$} \\
\hline A & 2 & $\mathrm{X}$ & $\mathrm{X}$ & $\mathrm{X}$ & $\mathrm{X}$ & $\mathrm{X}$ & $\mathrm{X}$ & $\mathrm{X}$ & $\mathrm{X}$ & $\mathrm{X}$ \\
\hline B & 5 & $\mathrm{X}$ & $\mathrm{X}$ & $\mathrm{X}$ & $\mathrm{X}$ & $\mathrm{X}$ & $\mathrm{X}$ & $\mathrm{X}$ & $\mathrm{X}$ & $\mathrm{X}$ \\
\hline $\mathrm{C}$ & 10 & 200 & 6.4 & 11 & 100 & 55 & 460 & $1,769,314$ & 12.5 & 87 \\
\hline $\mathrm{D}$ & 15 & 200 & 10.8 & 14 & 100 & 67.5 & 444 & $1,553,410$ & 15.8 & 91 \\
\hline $\mathrm{E}$ & 20 & 200 & 16.2 & 16.7 & 100 & 77.14 & 425 & $2,265,951$ & 20.8 & 98 \\
\hline \multicolumn{11}{|c|}{$N=50$} \\
\hline A & 2 & $\mathrm{X}$ & $\mathrm{X}$ & $\mathrm{X}$ & $\mathrm{X}$ & $\mathrm{X}$ & $\mathrm{X}$ & $\mathrm{X}$ & $\mathrm{X}$ & $\mathrm{X}$ \\
\hline B & 5 & $\mathrm{X}$ & $\mathrm{X}$ & $\mathrm{X}$ & $\mathrm{X}$ & $\mathrm{X}$ & $\mathrm{X}$ & $\mathrm{X}$ & $\mathrm{X}$ & $\mathrm{X}$ \\
\hline $\mathrm{C}$ & 10 & 200 & 5.8 & 11 & 100 & 53 & 443 & $1,674,550$ & 11.7 & 91 \\
\hline $\mathrm{D}$ & 15 & 200 & 11.1 & 14 & 100 & 69.37 & 456 & $2,301,839$ & 17 & 93.7 \\
\hline $\mathrm{E}$ & 20 & 200 & 16.4 & 16.7 & 100 & 78.09 & 430 & $1,602,688$ & 21 & 100 \\
\hline
\end{tabular}

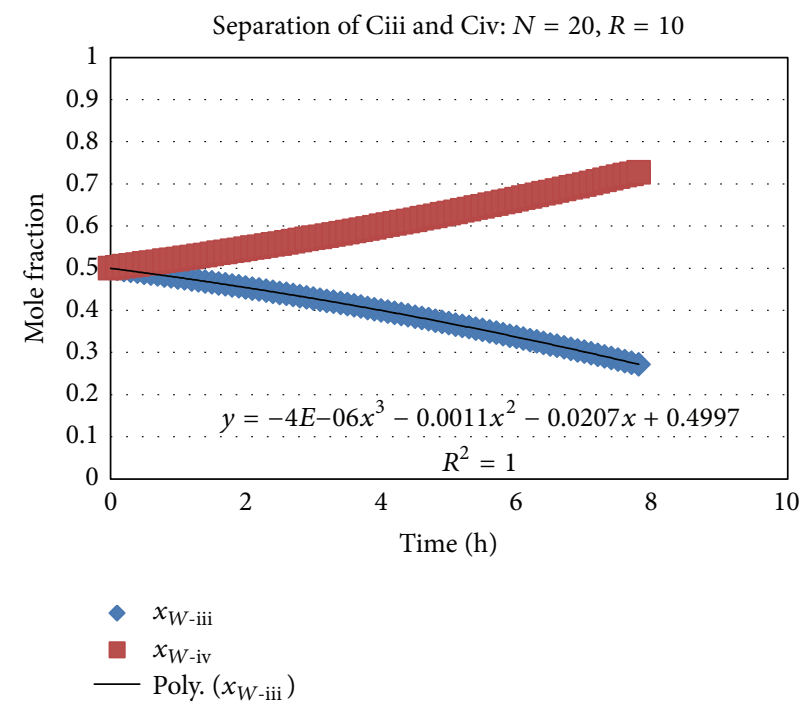

(a)

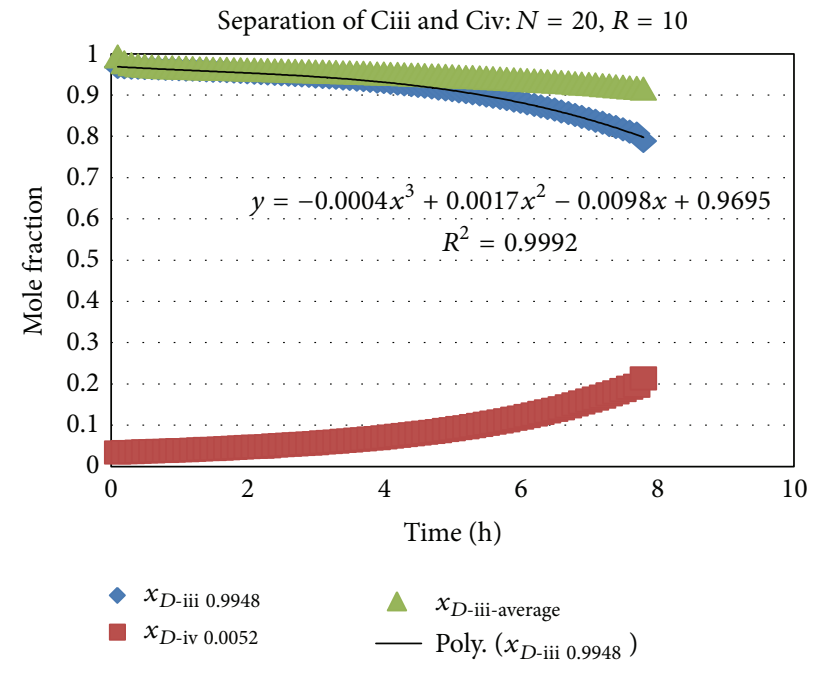

(b)

FIGURE 5: Results for two components (ethylbenzene and o-xylene) batch distillation at $N=20$ and $R=10$. 


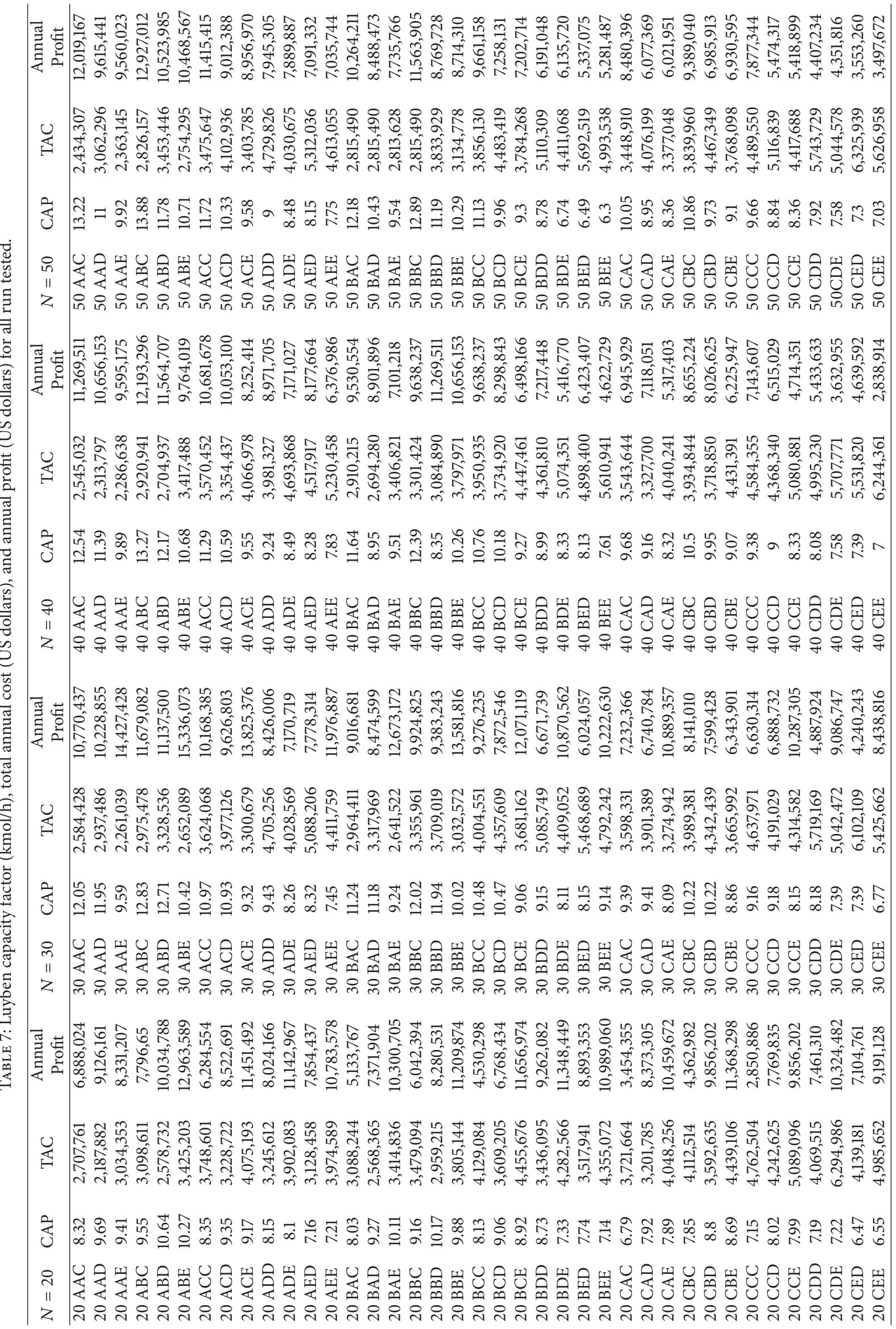




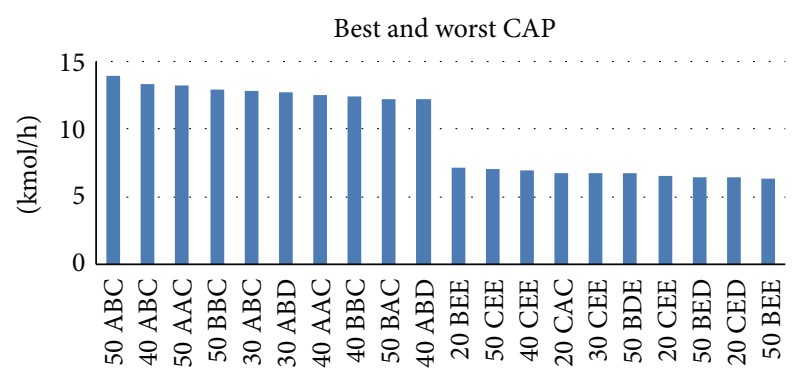

(a)

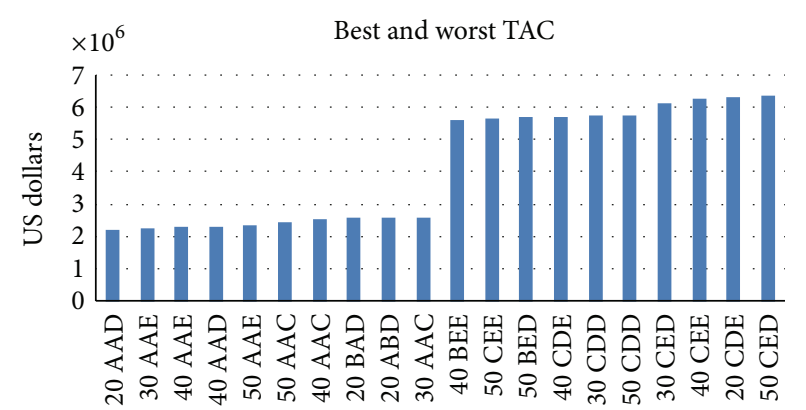

(b)

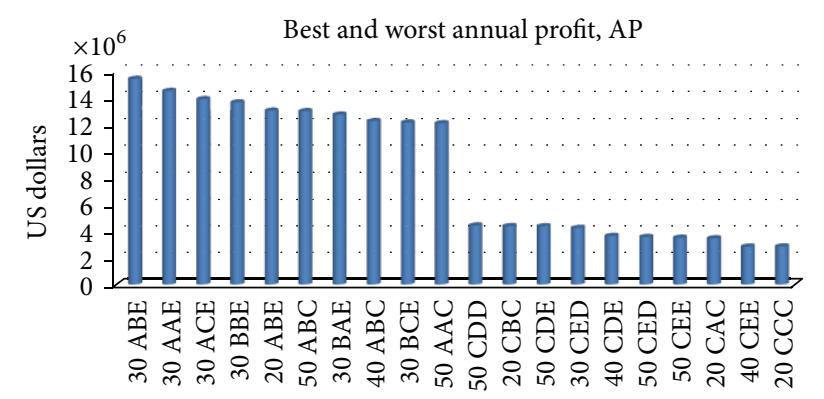

(c)

FIGURE 6: Best and worst cases for luyben capacity factor (CAP), total annual cost (TAC), and annual profit (AP).

\section{Analysis}

At the beginning of this project only two qualifying parameters: Luyben's capacity factor (CAP) and total annual cost (TAC) were used. The best combinations of theoretical stages and reflux ratio only coincided when using low reflux ratio, probably a reflux slightly above minimum reflux, but it was not clear which number of stages was optimum. Using CAP, batch distillation columns with high number of trays were recommended for eight of the ten best cases, probably because for high number of plates $\mathrm{N}$, the reflux ratio could be small.

Using total annual cost, the best runs used 20 and 30 theoretical stages, although half of the best options used 40 and 50 theoretical stages.

Reading the new Diwekar's book [20] and Diwekar and Madhavan paper [21] we see that optimization is described as a three-step process, and that in the second step a measure for system effectiveness is needed. They propose annual profit given by (15), but calculated in a different form. Because we already had the total annual cost, we only needed to calculate the total annual income that was related to Luyben's capacity factor.

We observed that CAP recommends many and TAC recommends few theoretical stages. The combination with highest annual profit AP combined a regular number of theoretical stages (30) and a reflux slightly higher than the minimum, close to $1.2 R_{\text {min }}$.

There were also good combinations with low (20ABE) and high $(50 \mathrm{ABC})$ theoretical stages.

\section{Conclusions}

The equations required to simulate the short-cut method are few and are easy to program and use in a short computer program that uses relative volatilities as the parameter to predict both the liquid vapor equilibrium and the difficulty of separation. With the short-cut method many cases can be solved by varying the number of theoretical stages and the value of reflux ratio.

To select the best combination, three quality indexes were compared: Luyben's capacity factor, total annual cost, and annual profit. The best combination always required a reflux ratio close to the minimum, which is analogous to the optimum operational reflux equal to 1.1-1.2 times the minimum reflux ratio for continuous distillation columns.

The best qualifying parameter was annual profit and, as it used the other two for its calculation, we believe it is representative of the process.

The best combination was case 30ABE. It used a distillation column with 30 plates and a column diameter of $0.91 \mathrm{~m}$, with reflux ratio's of 2.0 (A) for the first separation of four components, 5.0 (B) for the second separation of three components, and 20 (E) for the last separation of two components. The cost of this stainless steel column was estimated at $\$ 358,520$ USD in 2012 . It requires a condenser with an area of $35.85 \mathrm{~m}^{2}$ at an approximated cost of $\$ 119,100$ USD. The required stainless steel reboiler should have $119.74 \mathrm{~m}^{2}$ of area and an estimated cost of $\$ 810,400$ USD. With a depreciation of 0.10 per year the total annual cost is $\$ 128,802$ USD.

The mass flow rate of cooling water and steam required are 80,087 and $2,443,200 \mathrm{~kg} /$ year, respectively, providing an 
annual operational cost of $\$ 2,523,287$ USD. Overall, the total annual cost is $\$ 2,652,089$ USD.

The annual income of the four components was calculated at $\$ 17,988,162$ USD and subtracting to this value TAC, it should provide an annual profit of $\$ 15,336,073$ USD before taxes.

From the three quality indexes used only annual profit allowed the selection of the best economical alternative.

\section{Nomenclature}

$a, b, c, d, e:$
$A_{d}:$
$A_{C}:$
$\mathrm{AP}:$
$A_{R}:$
$\mathrm{CAP}:$
$C_{P-\mathrm{CW}}:$
$\mathrm{D}:$
$D_{\mathrm{col}}:$
$f:$

Constants for Antoine equation (1) with $T$ in $(\mathrm{K})$ and $P$ in $\mathrm{mm} \mathrm{Hg}$ Area of downcomer $\mathrm{m}^{2}$ Area of condenser $\mathrm{m}^{2}$ Annual profit USD Area of reboiler $\mathrm{m}^{2}$ Luyben capacity factor $\mathrm{kmol} / \mathrm{h}$, or $\mathrm{kg} / \mathrm{h}$

$$
\text { Heat capacity of cooling }
$$$$
\text { water } \mathrm{K} / \mathrm{kg}-\mathrm{K}
$$

Distillate kmol

$f:$

Diameter of column m

Fraction operational vapor

velocity dimensionless

(i), (ii), (iii), (iv): Benzene, toluene, ethylbenzene, xylene

$K:$ Equilibrium constant

$L:$

$M_{\mathrm{CW}}$ :

$M_{V}$

$M_{\text {steam }}$ :

$N$ : $(y / x)$ dimensionless Liquid flow kmol/s

Flow rate of cooling water $\mathrm{kg} / \mathrm{s}$

Molecular mass $\mathrm{kg} / \mathrm{kmol}$

Flow rate of steam kg/s

$N_{C}:$

theoretical stages dimensionless

Number of

$N_{\text {min }}$ :

components dimensionless

Minimum number of theoretical stages dimensionless

$P_{j}^{S}:$

$P:$

$Q_{C}:$

$Q_{R}$ :

$R$ :

$R_{\min }$ :

$t:$

$t_{E}:$

$t_{F}$ :

$t_{P}$ :

TAC:

$T_{\mathrm{CW}}$ :

$T_{R}$ :

$U:$

$U:$

$U_{f}:$

$V:$
$X$ : Mole fraction on liquid dimensionless

$y$ : Mole fraction in vapor dimensionless

$W$ : Liquid at bottom of column kmol.

\section{Greek Letters}

$\alpha_{i j}$ : Relative volatility $(K i / K j)$ dimensionless

$\rho: \quad$ Density $\mathrm{kg} / \mathrm{m}^{3}$

$\mu: \quad$ Viscosity $\mathrm{kg} / \mathrm{m}-\mathrm{s}$

$\Delta H$ : Heat of condensation or vaporization $\mathrm{J} / \mathrm{kg}-\mathrm{K}$.

\section{Subscripts}

0: Starting time

$j$ : Component

$F$ : Feed

L: Liquid phase

$D$ : Distillate

$W$ : Bottom.

\section{Acknowledgments}

The authors acknowledge David Caliz Rodriguez (Student of Instituto Tecnologico de VillaHermosa, Mexico) for the implementation of the first Excel computer program in 2011 Scientific Summer Mexican Program and Jessica Ortiz Palafox (Student of FIQ-UADY) for the implementation of the computer program in Mathcad to estimate distillation column parameters and cost functions.

\section{References}

[1] U. M. Diwekar, Simulation, design, and optimization of multicomponent batch distillation columns [Ph.D. thesis], Indian Institute of Technology, Bombay, India, 1988.

[2] U. M. Diwekar and K. P. Madhavan, "Multicomponent batch distillation column design," Industrial \& Engineering Chemistry Research, vol. 30, no. 4, pp. 713-721, 1991.

[3] S. Sundaram and L. B. Evans, "Shortcut procedure for simulating batch distillation operations," Industrial \& Engineering Chemistry Research, vol. 32, no. 3, pp. 511-518, 1993.

[4] M. R. Fenske, "Fractionation of straight-run Pennsylvania gasoline," Industrial \& Engineering Chemistry, vol. 24, pp. 482485, 1932.

[5] A. J. V. Underwood, "Theory and practice of testing stills," Transactions of the Institution of Chemical Engineers, pp. 112158, 1932.

[6] A. J. V. Underwood, "Fractional distillation of multi-component mixtures. Calculation of minimum reflux ratio," Journal of the Institute of Petroleum, vol. 32, pp. 614-626, 1946.

[7] E. R. Gilliland, "Multicomponent rectification," Industrial \& Engineering Chemistry, vol. 32, pp. 1101-1106, 1940.

[8] M. Barolo and G. B. Guarise, "Batch distillation of multicomponent systems with constant relative volatilities," Chemical Engineering Research and Design, vol. 74, no. 8, pp. 863-871, 1996.

[9] J. D. Seader and E. J. Henley, Separation Process Principles, John Wiley \& Sons, 1st edition, 1998. 
[10] J. D. Seader and E. J. Henley, Separation Process Principles, John Wiley \& Sons, 20 edition, 2006.

[11] W. L. Luyben, "Some practical aspects of optimal batch distillation design," Industrial and Engineering Chemistry Process Design and Development, vol. 10, no. 1, pp. 54-59, 1971.

[12] M. S. Al-Tuwaim and W. L. Luyben, "Multicomponent batch distillation. 3. Shortcut design of batch distillation columns," Industrial and Engineering Chemistry Research, vol. 30, no. 3, pp. 507-516, 1991.

[13] Y. K. Molokanov, T. P. Korablina, N. I. Mazurina, and G. A. Nikiforov, "Approximation method for calculating the basic parameters of multicomponent fractionation," International Chemical Engineering, vol. 12, no. 2, pp. 209-212, 1972.

[14] H. E. Eduljee, "Equations replace gilliland plot," Hydrocarbon Processing, vol. 54, no. 9, pp. 120-122, 1975.

[15] I. M. Mujtaba, Batch Distillation Design and Operation, Imperial College Press, 2004.

[16] J. Gmehling, U. Onken, and W. Arlt, Vapor-Liquid Equilibrium Data Collection, Aromatic Hydrocarbons, vol. 1, part 7, 7a, 7b, DECHEMA, 2000.

[17] C. L. Yaws, Physical Properties, Chemical Engineering, Mc Graw Hill, 1977.

[18] R. Turton, R. C. Bailie, W. B. Whiting, and J. A. Shaeiwitz, Analysis, Synthesis, and Design of Chemical Processes, Prentice Hall, 2003.

[19] M. S. Peters and K. D. Timmerhaus, Plant Design and Economics for Chemical Engineers, McGraw-Hill, 4th edition, 1991.

[20] U. M. Diwekar, Batch Distillation, Simulation, Optimal Design, and Control, CRC Press, 2012.

[21] U. M. Diwekar, K. P. Madhavan, and R. E. Swaney, "Optimization of multicomponent batch distillation columns," Industrials and Engineering Chemistry Research, vol. 28, no. 7, pp. 1011-1017, 1989. 

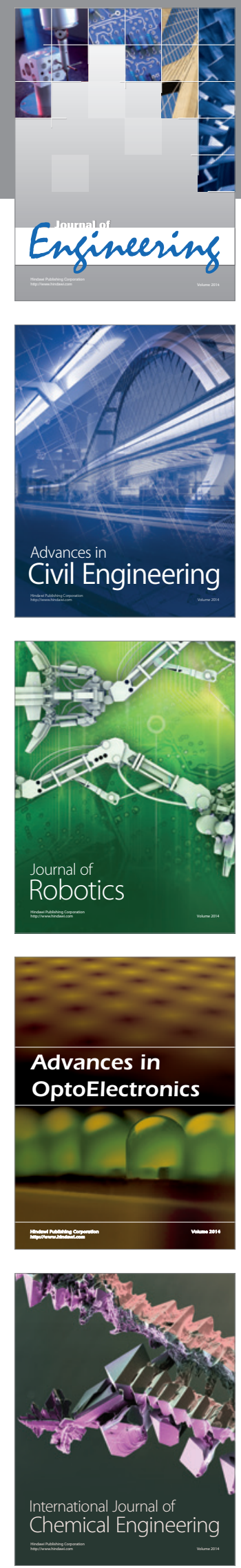

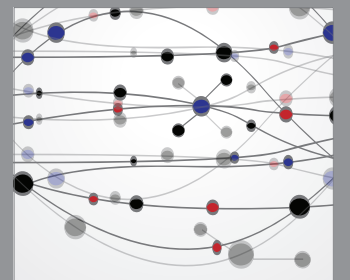

The Scientific World Journal
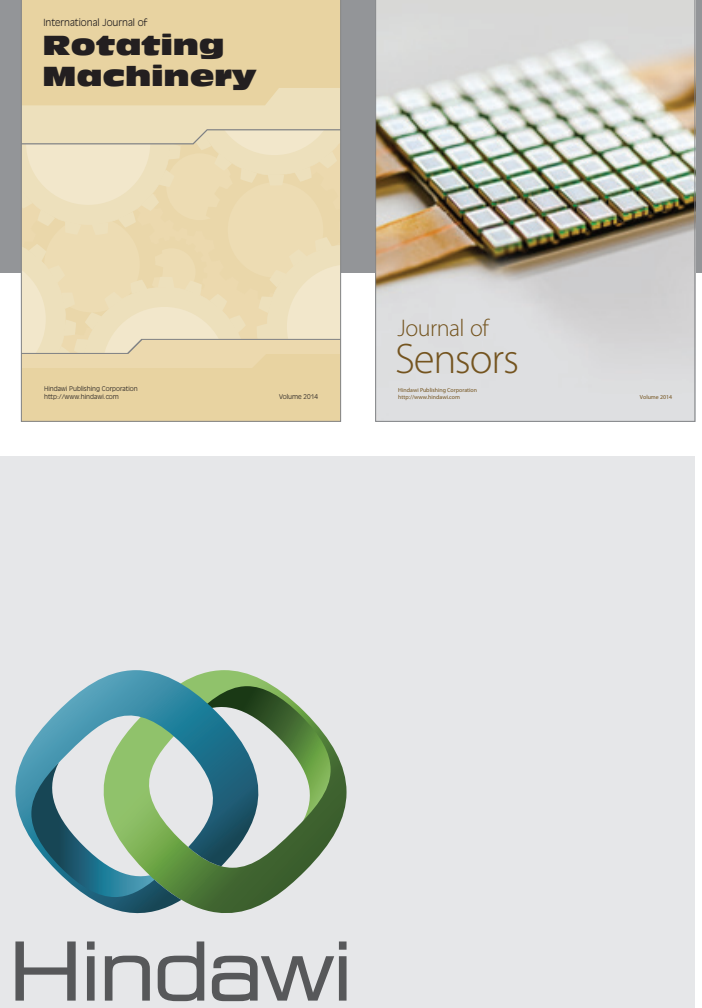

Submit your manuscripts at http://www.hindawi.com
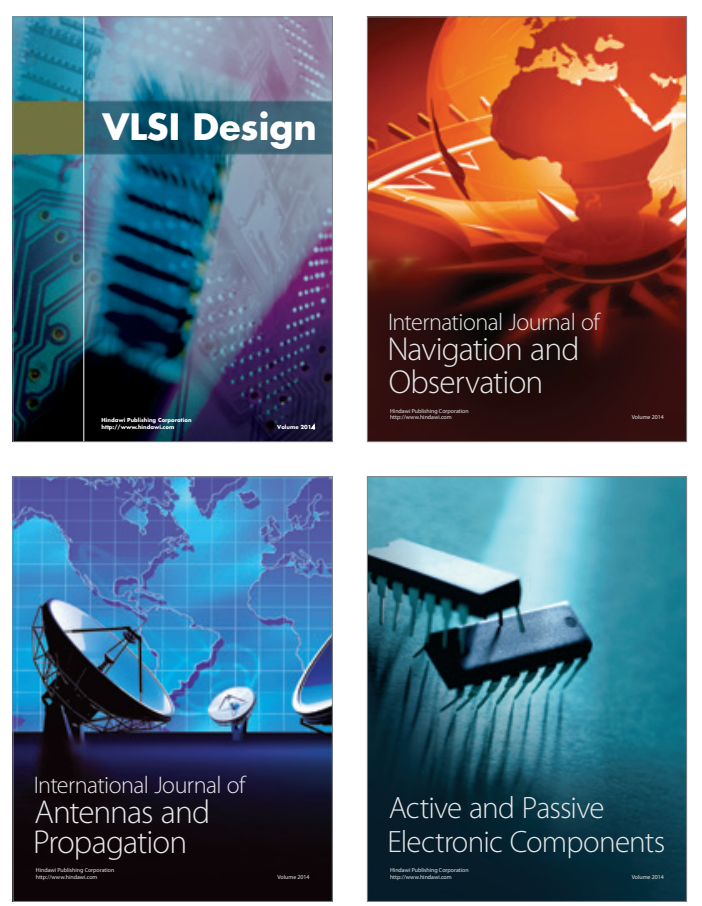
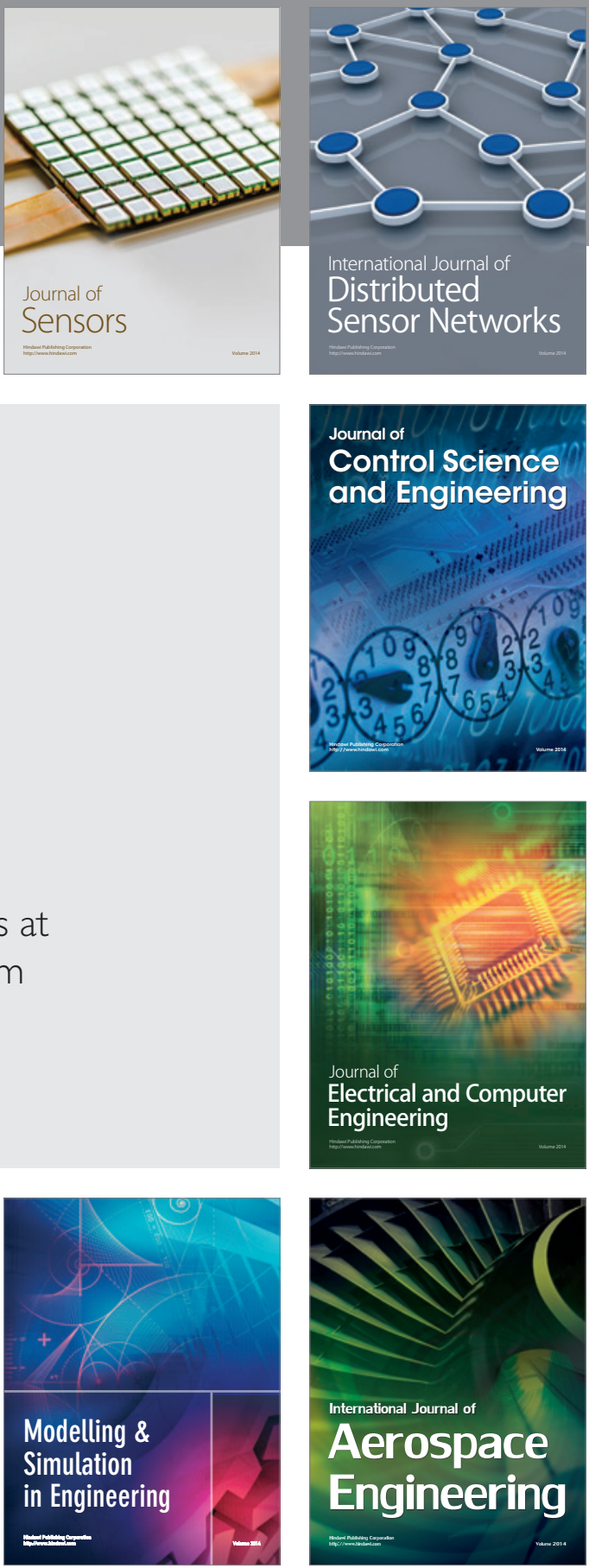

Journal of

Control Science

and Engineering
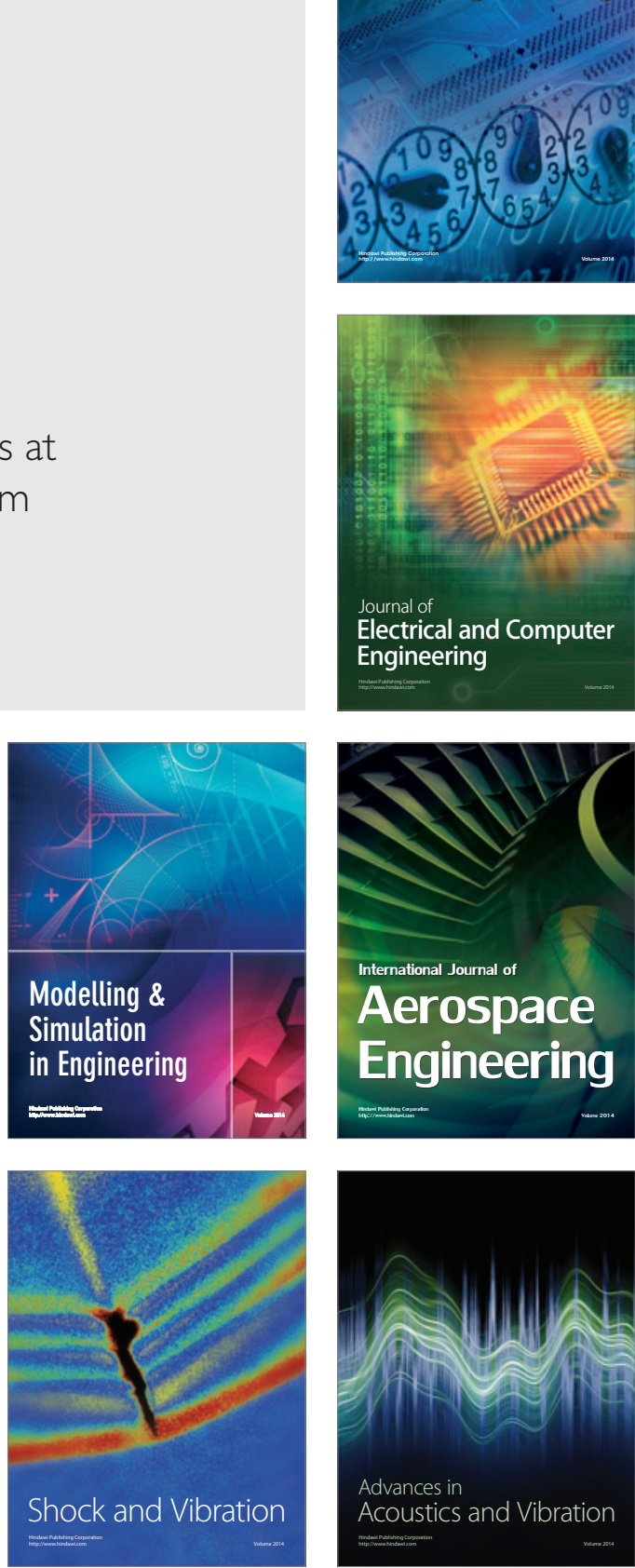